\title{
EFFECTIVENESS HARBOUR TUG FLEET: PROBLEM FORMULATION AND METHODOLOGY OF ITS SOLUTION
}

\author{
UDC 629.5.(05) 629.561.11:629.5.016.8 \\ Original scientific paper
}

\begin{abstract}
Summary
The article deals with the current problem of improving the effectiveness of the harbour tug fleet. The methodology of the selection of optimal structure of the tug assistance has been suggested. It is based on the methods of statistical modelling, the queuing theory and the theory of the ship design, as well as algorithms developed by the authors. The method of calculating forces, which act on the ships during their movement to the port berths, and the transfer of these forces to the required total bollard pull of tugs is described. The method for calculating the economic performance of the harbour tugs used in harbour towage is considered. The algorithm for the development of the order with the determination of the required number of tugs to carry out towing operations in the current hydrometeorological conditions of the port is suggested. The model of the functioning of the harbour tugs is developed. The optimization problem of the determination of the required structure of the harbour tug fleet is formulated and solved. The findings of the study results are suggested for the optimization of the existing or renewed tug assistance of the port, selection of the design characteristics of harbour tugs on the conceptual stages design.
\end{abstract}

Key words: $\quad$ bollard pull; effectiveness; harbour towage; harbour tug; methodology; modelling; model of functioning; optimization; port; tug assistance

\section{Introduction}

Ship design and determination of their effectiveness and operational reliability is associated with the analysis of the functional operations performed. As a result of this analysis the best of them are selected, intended for the independent operation as well as the operation in the fleet. A feature of the port tugs is that the level of their effectiveness and safety are most of all realized during the complex consideration of the functioning of the harbour tug fleet as a whole, rather than individual tugs.

The structure of the tug fleet in the port depends on the number of entering ships and their deadweight, geographical location as well as the level of technological equipment of 
berths. Moreover, the accepted norms of the tug assistance on mooring / unmooring and tug escorting affect the number of tugs. In different countries there are different approaches to the development of norms or stating the quantitative structure of tugs for towing operations. The first approach, adopted in Russia and Ukraine, is based on the use of guidance documents [1], [2] setting the number of tugs and the power of their main engines, depending on the type of the ship and its tonnage. The second approach adopted in many ports of the world is based on the use of approximate dependencies and various tables or charts to estimate the required characteristics of tugs [3], [4]. Both approaches have their advantages and disadvantages. For example, the selection of tugs is performed on the basis of power of their main engines, and not bollard pull, but a modern tug with less power may have the bigger bollard pull than the tug with the bigger power of the earlier years of construction. Indeed, the bollard pull of the tug depends on the type of propulsion: the propeller, the azimuth thruster, the cycloidal propulsion. Also, in many cases, norms of tug assistance are stated on the basis of the limit wind and wave values without taking into consideration the individual characteristics of the port: the area of location, climate, and so on.

Thus, at present it is a very urgent problem of development of methodology of the development of the optimal structure of the harbour tug fleet, as well as the method of calculation of the required number and the bollard pull of tugs to perform mooring operations for a particular port and current weather conditions.

The solution of this problem should obviously comply with the balance, which is formed in the operating environment (the environment of functional operations) of the port under consideration. Since each port is substantially different from one another, the requirements for the number and power of port tugs should be formed individually. At that the use of more powerful tugs associated with an increase in investment for their acquisition and the increase of cost for the operation, becomes justified at the corresponding increase in the productivity of port and servicing the ships with characteristics caused by the increase in productivity of the port.

The most promising way, according to the authors, is an integrated approach with the use of capabilities of simulation modeling, and the development of the structure of the harbor tug fleet should be carried out by modeling its work based on the number and characteristics of the processed ships, hydrometeorological conditions.

\section{Literature review}

The performed analysis of studies and publications suggests small amount of scientific papers on the subject. First of all we should consider the work of Hansen [3], which includes the data on different ports of the world and suggests graphs for selecting the number of tugs and their bollard pull, depending on the type of ship and its deadweight. It also provides recommendations on the calculation of the required bollard pull of tugs. Some dependencies on the evaluation of the bollard pull of tugs are given in the works of [5], [6] and [7]. At the same time, these articles do not consider the issue of selecting the optimal structure of the tug assistance of the port.

The works [8], [9], [10] are connected with the selection of the design characteristics of port tugs. They contain sufficient detail on the issues of conceptual design of various types of tugs. At the same time the works do not consider the research design of port tugs - the bollard pull selection, the number for a particular port, taking into account the geographical location, climatic conditions, the deadweight of the entering ships and the specifics of the implementation of mooring operations.

The issues of simulation of towing operations and functioning of the port are considered in the following articles [11], [12], [13]. 
The most comprehensive study is the work of [14] in which the author suggested the methodology of selecting the optimal structure of the tug assistance of the port. The main disadvantage of this approach is the use of the deterministic approach. But, as statistics show, the number of ship entering to the port, the time of operation are random variables.

That is why the article aim is the development of the methodology for the selection of optimal number and characteristics of harbour tugs.

\section{Methodology}

The methodology for the selection of the optimal structure of the harbour tug fleet from the point of view of economic efficiency is developed by the authors. It is based on:

1. The method of calculating the forces acting on the ships during their movement to the harbour berths and transferring of these forces to the required total bollard pull of tugs.

2. The algorithm for the development of the order with the determination of the required number of tugs to carry out towing operations in the current hydrometeorological conditions of the port.

3. The model of functioning of the harbour tug fleet.

4. The algorithm for calculating the economic performance of the harbour tugs.

5. The formulation and solution of the fundamentally new optimization problem of the determination of the required structure of the harbour tug fleet.

3.1 Method of calculation of the required total bollard pull of tugs for performing towing operations

The main factors affecting the total required bollard pull of tugs are the following: the size of the assisted ship, aerodynamic forces acting on its above-water part, hydrodynamic forces acting on the submerged part of the hull, as well as inertial forces caused by changes in the speed of the ship as it moves in harbour waters.

The correct determination of these forces is provided not only by the selection of a sufficient number of tugs and values of their bollard pull, but also by the coordination of the processes of the ship movement modelling with the full-scale data of its towages in harbour waters.

The method of "covering" all possible design schemes by one scheme that allocates the most critical stages of the mooring-unmooring operations usually accompanied by the largest developed forces is used in the given methodology for the determination of the required number of harbour tugs. Among the many stages of towing the ship assisted by tugs, the most critical in constrained harbour waters are usually the final stage of mooring and the initial stage of unmooring. In both cases, the ship is located parallel to the berth and the developed forces are oriented in a perpendicular direction to its centreline plane. This design situation is traditionally taken as a basis for all methodologies of selecting the required number and power of harbour tugs [3], [15], [16].

The implementation of the design scheme is achieved in stages by determining the forces from wind and wave action, and the ones caused by the movement of the ship and inertia of the processes of its braking and accelerated movement. The final value of the force which determines the required bollard pull of tugs according to the displacement or deadweight of the moored/unmoored ship is calculated by the formula:

$$
F=S_{f}\left(F_{1}+F_{2}+F_{3}+F_{4}\right)
$$


where $S_{f}$ is the operational safety factor; $F_{1}$ is the wind forces, $\mathrm{t} ; F_{2}$ is the wave forces, $\mathrm{t} ; F_{3}$ is the hydrodynamic forces, $\mathrm{t} ; F_{4}$ is the inertial forces, $\mathrm{t}$.

The wind forces acting on a ship is determined by the following formula [3], [15], [16]:

$$
F_{1}=\frac{1}{2} \frac{C_{Y W} \rho_{1} V_{1}^{2} A_{L}}{g 10^{3}},
$$

where $\rho_{1}$ is the air density, $\mathrm{kg} / \mathrm{m}^{3}, V_{1}$ is the wind velocity, $\mathrm{m} / \mathrm{s}, A_{L}$ is the broadside or lateral projected wind area, $\mathrm{m}^{2}, C_{Y W}$ is the wind force coefficient.

The values of the wind velocities at the current time $V_{1}$ is generated by a random number generator in accordance with the given probability distribution function. Lateral projected wind area shall be calculated depending on the type of ship, its deadweight and load case: "in loaded" or "in ballast" [17], [18].

For an approximate assessment of the components of wave forces in the practice of designing of ports, the following formula is used [3], [15], [16]:

$$
F_{3}=0,112 L_{B P} H_{1 / 3}^{2},
$$

where $L_{B P}$ is the length between perpendiculars of the ship, $\mathrm{m} ; H_{1 / 3}$ is the significant wave height, $\mathrm{m}$.

The hydrodynamic force acting on the submerged part of the hull of the ship moving in the harbour waters is calculated by the formula [3], [15], [16]:

$$
F_{2}=\frac{1}{2} \frac{C_{Y C} \rho_{2} V_{2}^{2} A_{L C}}{1000 g}
$$

where $\rho_{2}$ is the density of sea water, $\mathrm{kg} / \mathrm{m}^{3}, V_{2}$ is the velocity of the ship at mooring, $\mathrm{m} / \mathrm{s}, A_{L C}$ is the projection of the submerged part of the hull to the centreline plane, $\mathrm{m}^{2}, C_{Y C}$ is the hydrodynamic resistance coefficient.

The determination of the values of the hydrodynamic force is performed with the following data: $\rho_{2}=1025 \mathrm{~kg} / \mathrm{m}^{3}, V_{2}=0,3 \mathrm{~m} / \mathrm{s}, C_{Y C}=0,7$.

The value of $A_{2}$ area is determined depending on the type and deadweight of the ship and its load case ("in loaded" or "in ballast") [17], [18].

The ship moves lagged at variable speed in the process of the considered stages of mooring. The emerging at this time mass and hydrodynamic inertial forces are determined by the value of the ship displacement and "added" mass. In the practice of designing ports, the total inertial load, required for completing the ship movement when mooring or for acceleration to a specific value at unmooring, is suggested to be calculated by the formula [3], [15], [16]:

$$
F_{4}=f_{4} \frac{0,07 \Delta V_{4}^{2}}{S_{4}},
$$

where $f_{4}$ is the inertial coefficient which is assumed to be equal $f_{4}=1,6$ for marine cargo ships, $V_{4}$ is the initial or final velocity, the recommended value of which is $V_{4}=0,5 \mathrm{kn}$ 
( $V_{4}=V_{0}=0,26 \mathrm{~m} / \mathrm{s}$ ), $\Delta$ is the displacement of the ship, $\mathrm{t}, S_{4}$ is the distance of the ship movement, $S_{4}=S_{0}=40 \mathrm{~m}$.

3.2 Algorithm for the development of the order with the determination of the required number of tugs

To solve the problem of the selection of the optimal number of the harbour tug assistance, an algorithm for the development of the order was developed, providing the required bollard pull and satisfying the following conditions [14]:

- the required total bollard pull of tugs used in the towage operation should not exceed the actual bollard pull of the selected tugs;

- the number of tugs used in the towage operation should be not less than 2 and not more than 5;

- the use of tugs only from related groups (limited by bollard pull) is allowed in one towing operation.

The process of the order development begins with the determination of the minimum number of tugs $N_{\min }$. For the ships with deadweight of less than $150000 \mathrm{t}$, two tugs are appointed, in other case, three are. It is assumed that first the tugs selected from the same group. Next, the minimum required bollard pull of one tug is determined

$$
Z=\frac{Z_{\text {req }}}{N_{\text {min }}}
$$

and the selection of the tugs is conducted by the condition

$$
Z_{j} \geq Z
$$

where $Z_{\text {req }}=F$ is the total bollard pull of tugs which is calculated using the formula (1).

If there are no available tugs with a bollard pull equal to or greater than $Z$, than the minimum number of tugs per unit increases. The operation of incensement continues till the maximum allowable number of tugs in the order is exceeded or the condition (7) fulfils. In the first case, a message about the absence of available tugs is given and the ship is queued for service in waiting of the free required tugs.

In the second case, the selection of tugs in the cycle is conducted by the formula

$$
Z_{j} \geq Z_{\mathrm{req}_{j}}
$$

where $j$ is the sequence number of the tugs in the order $\left(j=1, \ldots, N_{\min }\right), Z_{\mathrm{req}_{j}}$ is the required bollard pull for the $j$-th tug:

$$
Z_{\mathrm{req}_{j}}=\frac{Z_{\mathrm{req}}-Z_{\mathrm{sum}}}{N_{\text {min }}-j-1},
$$

$Z_{\text {sum }}$ is the total bollard pull of already selected tugs for towage.

The selected tugs are given the status "non-available".

Besides, the towage operation cannot be performed if the required number of tugs is greater than the number of tugs which are free at the current time. 


\subsection{Model of functioning of the harbour tug fleet}

The model of functioning of the harbour tug fleet is based on the methods of queuing theory [19], [20], [21] and simulation modeling [22], [23], [24]. It is assumed that the modelled "port" system consists of the following elements: "the approach channel", "berths" and "tugs". At this, the approach channel, berths and tugs are serving devices that can be in two states: "available" or "non-available". The arrival of ships at the port is considered as a arrival traffic distributed by berths and requiring service.

The set of the port berths is represented as a multichannel queuing system being in the random weather conditions at the random arrival traffic. The intensity of this traffic is determined on the basis of statistical data for the considered period (usually a calendar year).

For the distribution of the arrival traffic by berths, each berth is assigned with its own traffic rate (the number of moored ships at a unit of time (one year)) differentiated by the type of ships and their deadweight (Figure 1).

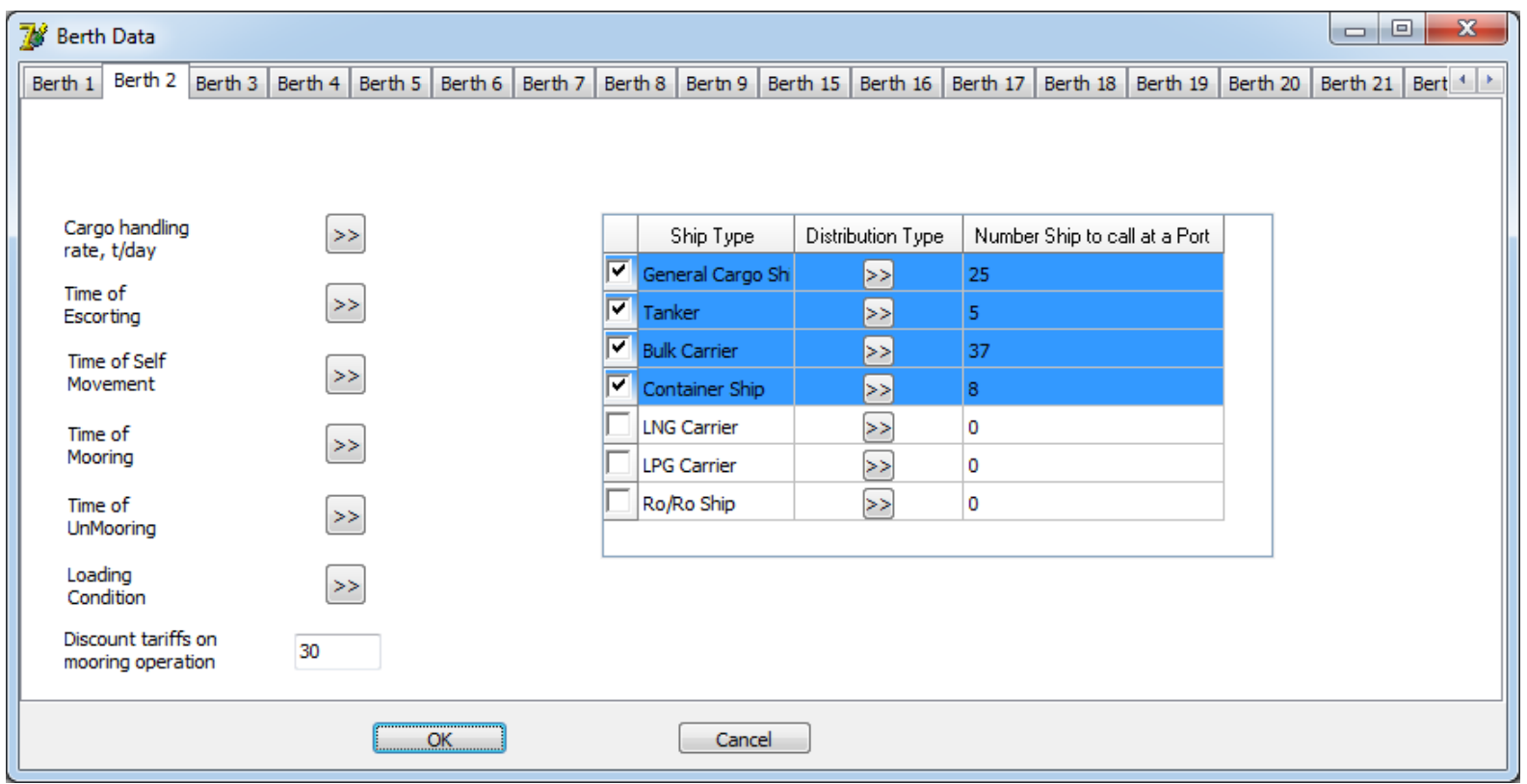

Fig. 1 Data on the traffic flow for the second berth

The random deadweight variable is determined by the probability distribution and its parameters. They are the average, variance, etc. As an example, a histogram of such distribution and its approximation by the log-normal law for dry cargo ships moored to the berth No. 2 of one of the Ukrainian ports with an intensity of an average of 25 ships per year is shown (Figure 2).

If the deadweight of the ships entering the port cannot be described by any of the known theoretical distribution, than the histogram (Figure 3) is used to generate the values of the random variable.

At the implementation of the model of functioning the time of occurrence of the next ship, i.e. service request, is generated for each berth. For the obtained arrivals, using formula (1), the total required bollard pull of harbour tugs is determined and their number is selected from the existing structure of the harbour tug fleet considering the usage of tugs in operations with other ships, depending on the type of ship, its deadweight and weather conditions at the time of the manoeuvring operations. The possibility of the entering of the ship to the port is verified. For this, the following conditions should fulfil: the berth should be "available", the channel - "available", the weather - "allowable" and there is a sufficient number of tugs with required bollard pull. 


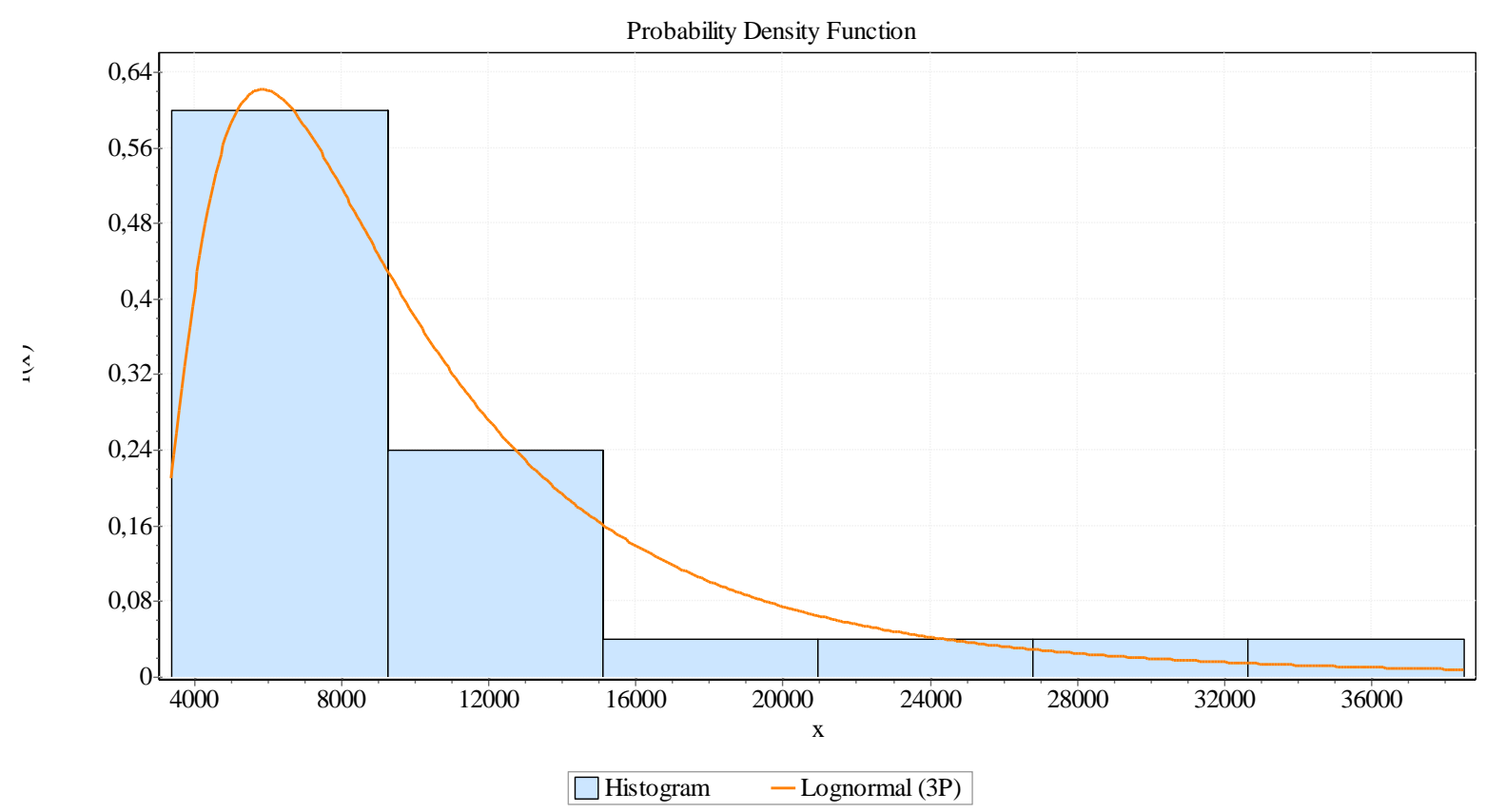

Fig. 2 Distribution of dry cargo ships by deadweight (berth No. 2)

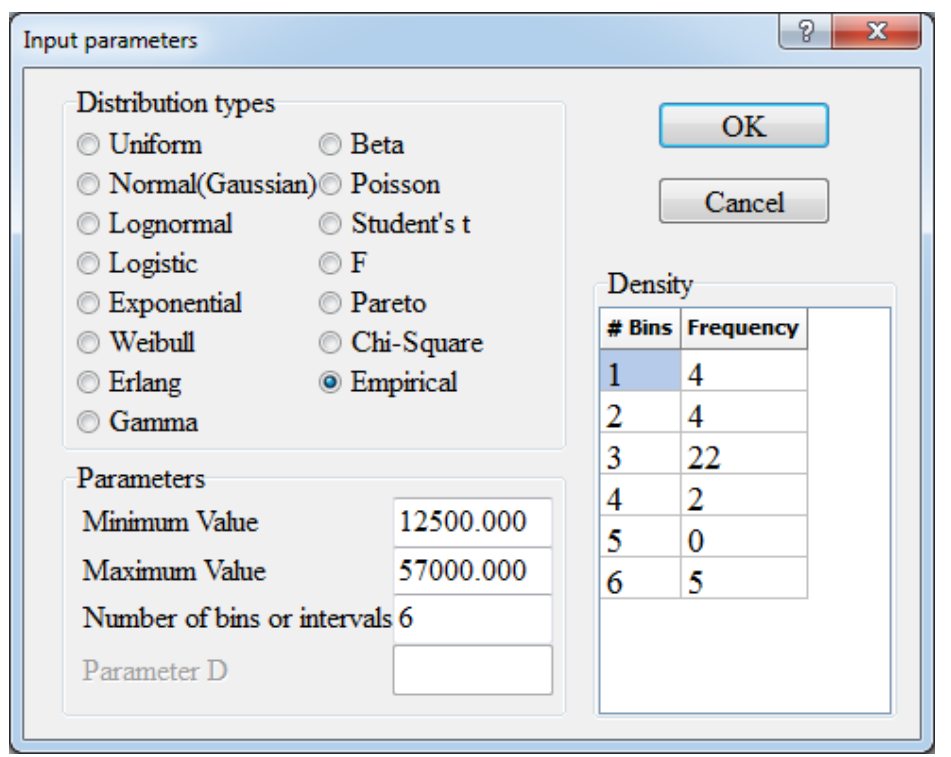

Fig. 3 Dialog window for the selection of the distribution of the random variable

If all these conditions are fulfilled, carrying out of the next stages of towage operations is modelled: escorting or assistance the ship along the approach channel, movement it to the berth and mooring. At this, status changes from "available" to "non-available" for the selected tugs and the intervals of time for carrying out the stages of towage operations are determined. The ship escort operation along the approach channel to the port entering is usually carried out with one tug, and assistance at the same location is performed with two tugs. The possibility of enabling other modes of navigation depending on the requirements of the port is foreseen. "Mooring" operation is conventionally taken as the movement of the ship from the port entering the berth. 
The random variables of intervals of time of performing the stages of towing operations are determined by the relevant probability distribution of time of escorting or accompanying, movement to the berth and mooring (berthing), as well as the parameters of this distribution, such as the average interval of time, its variance, etc. In the case of nonfulfillment of the conditions of the ship entering the port, the request is queued for service, i.e., "ship anchorage" event is modelled.

After completing the towing operations of escorting and movement of the ship to the berth, the tugs involved in escorting and movement become free (i.e., they get the "available" status).

The time of ship anchorage at the berth when the loading and unloading are carried out at the berth is modelled depending on the performance of the berth cargo equipment. The random variable of the performance of each berth is determined by the applicable distribution and its parameters.

After completing the loading and unloading, the possibility of the ship's unmooring from the berth is verified (availability of tugs and approach channel and the suitable weather conditions). If these conditions are nonfulfilled, the ship stays at the berth and waits for its turn for service.

If the required conditions for the departure of the ship from the port are met, than the required number of tugs (their status becomes "non-available") is selected from a number of available tugs, the intervals of time of unmooring operations and movement of the ship to the port exit (unmooring) and channel transit (escorting or assisting) are determined, the channel is given the "non-available" status and the modelling of towing operations is carried out.

The random variables of intervals of time of performing the stages of these towing operations are also determined by the relevant probability distribution of unmooring time and movement of the ship to the port exit, transit of the approach channel and parameters of the distribution.

The weather conditions for operating the port are set using the long-term probability distribution of wind velocities in the area of its geographical location.

The probability distribution of the characteristics of the port berth equipment are assessed by the average values of harbour berths performance and statistical data of the anchorage time of ships in the port for loading and unloading in a calendar year.

The time distribution of escorting the ship in the harbour approach channel, towing it from the port entering to the berths and back are also assessed according to the statistical data of the harbour tugs performance.

By the end of towing operations with the ship leaving the port, the request leaves the model, tugs and the channel are idle.

The modelling process is carried out in the interval of time equal to one calendar year, with a time step equal to one minute.

The state in which all berths are considered free, tugs - available, approach channel idle is taken as the initial state of the system.

The considered model of functioning of the harbour tug fleet is graphically represented in Figure 4 
Effectiveness harbour tug fleet: problem formulation and methodology of its solution
Oleksandr V. Bondarenko, Valery O. Nekrasov, Oleksii P. Yastreba

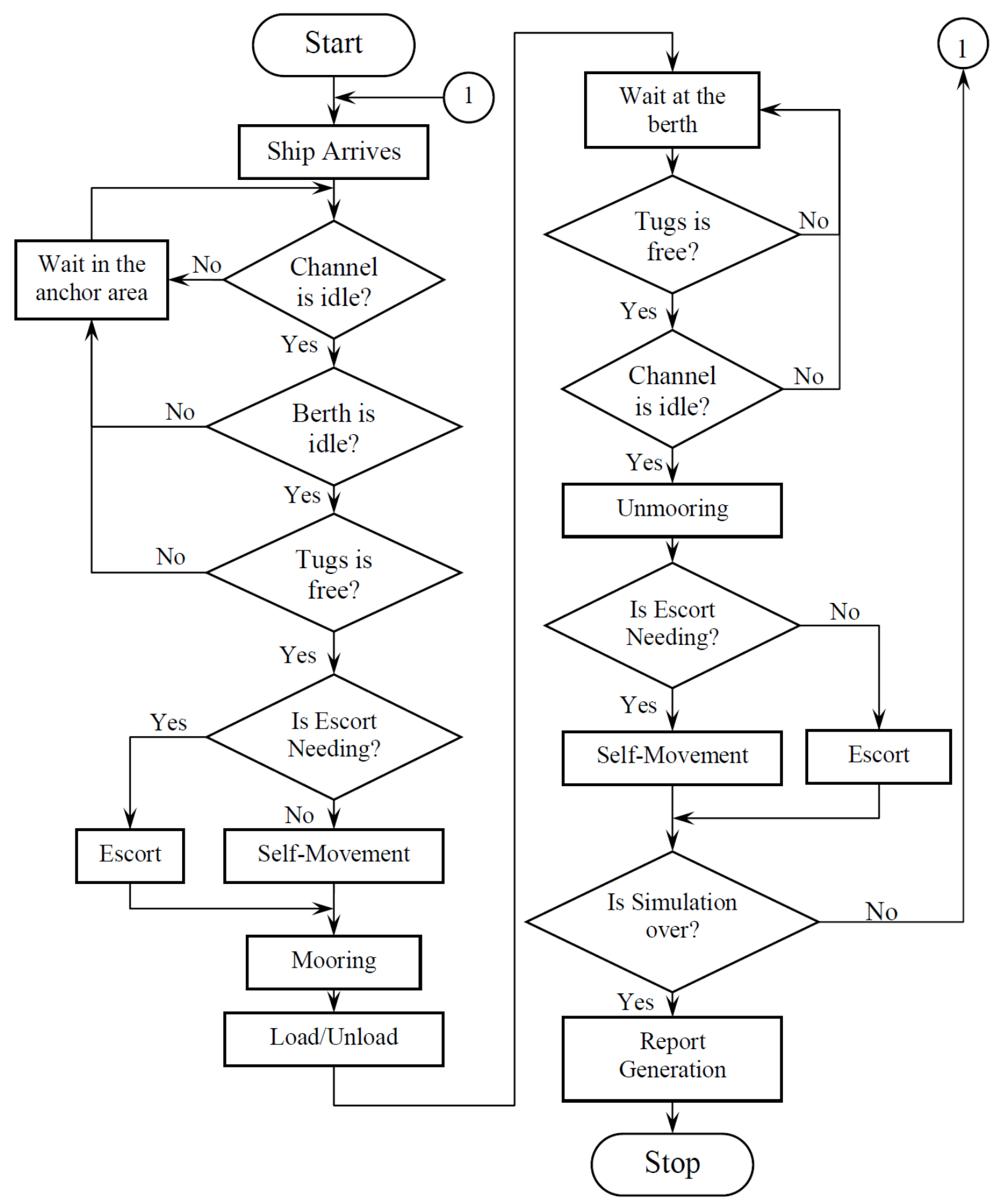

Fig. 4 Model of functioning of the harbour tug fleet

\subsection{Method of economic performance calculation of harbour tugs operation}

The developed model of functioning is extended by the block of calculation of the harbour tug performance. Performance evaluation is done by calculating the costs and revenues of harbour tugs at the performance of the following operations:

- escorting (assistance);

- mooring / unmooring / shifting; 
- waiting (delay).

The method takes into account the accumulation of all revenues from these operations, as well as the main items of operating costs. The costs are determined not by the maximum values of engine power of tugs, and current costs of power, required for the development of the required bollard pull, ensuring the implementation of the towing operation at the actual weather conditions, taking into account the additional force action due to the kinematics of the ship during the implementation of the current operation.

Taking into account the specifics of work, the revenue of the harbour tug is expected to consist of two components:

- Hourly rate assistance (escort);

- Payment for the execution of mooring operations (towing rate).

Operational cost of the harbour tug include the costs of fuel, crew salary and taxes, depreciation, repairs and maintenance, docking and classification survey.

Costs of repairs and maintenance are determined with the following formula

$$
C_{\mathrm{r} \& \mathrm{~m}}=\frac{q_{\mathrm{r} \& \mathrm{~m}} C_{\mathrm{TA}}}{100},
$$

where $q_{\mathrm{r} \& \mathrm{~m}}$ is the norm of the repairing and maintenance costs, $\%, C_{\mathrm{TA}}$ is the harbour tug total acquisition cost;

Costs of docking

$$
C_{d c}=\frac{q_{\mathrm{dc}} C_{\mathrm{TA}}}{100},
$$

where $q_{\mathrm{dc}}$ is the norm of the cost of docking, $\%$.

Depreciation cost

$$
C_{\mathrm{dp}}=\frac{q_{\mathrm{dp}} C_{\mathrm{TA}}}{100},
$$

where $q_{\mathrm{dp}}$ is the norm of the depreciation, $\%$.

Crew salary and taxes

$$
C_{\text {sal }}=12 s_{m} N_{\text {crew }}(1+\mathrm{enc}),
$$

where $N_{\text {crew }}$ is the crew number, $s_{m}$ is the crew average salary per month, enc is the social taxes.

Costs of fuel are determined with the following expression:

$$
C_{\text {fuel }}=\frac{S_{F C} N_{e} T}{1000000}
$$

where $S_{F C}$ is specific fuel consumption $\mathrm{g} /(\mathrm{kWh}), N_{e}$ is the required power of the tug main engines to perform port operations, $\mathrm{kW}, T$ is the time of the towing operation or the escorting operation, determined in the model of functioning, hours.

Based on the above, for the calculation of such performance indicator as the profit from the usage of the harbour tug fleet, in the first approximation we need to determine revenues 
from towing operations and tugs operating costs, that are expressed through the time of functional operations and the number of tugs used.

For the implementation of the suggested methodology the corresponding program has been developed. The main dialog window of the program is shown in Figure 5.

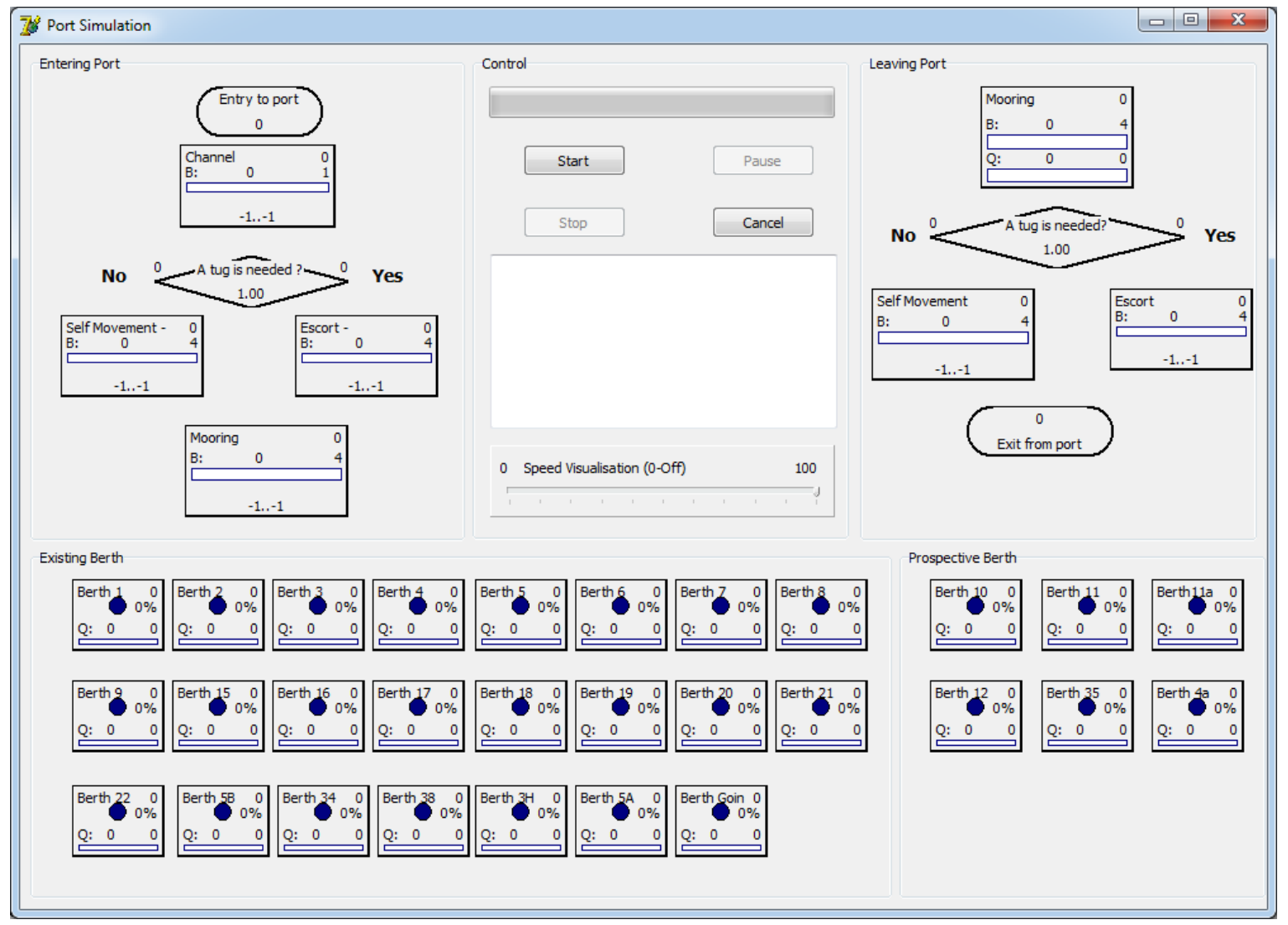

Fig. 5 The main dialog window of the program to determine the effectiveness of existing or appointed structure of tugs

3.5 Formulation and solution of the problem of selection of the optimal structure of harbour tug fleet

Methodology developed by the authors allows one to solve the problem of selection of the optimal structure of harbour tug fleet using two methods.

The basis of the first method is the development of the optimal structure of the harbour tug assistance from the existing harbour tugs as well as set preformed projects with wellknown pull characteristics. The matrix of tugs should contain the following information: the name of the tug, the number of crew, bollard pull, power, speed, acquisition cost, hourly rate, monthly crew salary, costs of repairs and maintenance, annual depreciation.

In this case, selection of the optimal structure of the port tug assistance is based on the analysis of the operation time of each type of tugs. Tugs with the minimal operation time should not be left in the fleet.

The second method provides a solution to the optimization problem. The number of tug types, which can be used to perform towing operations, is assumed to be known.

The index of the profit maximum or total bollard pull minimum can be selected as an objective function. 
The vector of independent variables includes: $Z_{i}$ is the bollard pull and $x_{i}$ is the number of tugs of the $i$-th type.

The system of constraints of the optimization problem contains the following requirements:

- to the number of tugs of the appropriate type

$$
x_{i}^{\min } \leq x_{i} \leq x_{i}^{\max },
$$

where $x_{i}^{\min }=0$ is the minimum number of tugs of the $i$-th type; $x_{i}^{\max }$ is the maximum number of tugs of the $i$-th type;

- to the bollard pull of tugs of the appropriate type

$$
Z_{i}^{\min } \leq Z_{i} \leq Z_{i}^{\max }
$$

where $Z_{i}^{\min }$ is the minimum bollard pull of tugs of the $i$-th type; $Z_{i}^{\max }$ is the maximum bollard pull of tugs of the $i$-th type. To solve the given optimization problem genetic algorithm [25], [26] is applied.

\section{Example of solving the problem of finding optimal characteristics of the harbour tug assistance}

The determination of the optimal characteristics of tugs and structure of the tug fleet of one of the ports of Ukraine is carried out by solving the optimization problem. The criteria of optimality in this problem are the minimum of the total bollard pull of the tug fleet at the given ship traffic flow and the maximum performance (profit) on the time interval, which is equal to the calendar year. The permissible difference among the number of ships in this interval which entered the port and departed from it is minimizing the damage to the ship owners from the delaying of a ship. This difference is used as the main limit of the problem.

The solutions of the optimization problem are obtained for the existing berthing complex and the complex of berths of the nearest future. The aim of these problems was to minimize the total bollard pull through the appropriate selection of tugs for each towing operation, generated in the actual weather conditions. At that the answers for three options of the port servicing are obtained:

- existing structure of tugs;

- with the exception of the most powerful tug from the existing structure of tugs, i.e. the tugs with a bollard pull of 75 tons;

- with the exception of two tugs from the existing structure of tugs. These tugs have bollard pull of 50 and 75 tons, but with the addition of tug with a bollard pull of 30 tons.

At the current structure of tugs the removal of two tugs with a bollard pull of 50 and 75 tons, compensated by adding the tug with a bollard pull of 30 tons proved to be the most profitable for the currently available berth complex. The annual notional profit in this case was found to be equal to 4,23; 5,04 and 5,59 million USD on the variants respectively.

The removal of only one powerful tug with a bollard pull of 75 tons led to the optimal state of the tug fleet for the prospective berth complex. At that, the notional profit on these variants was 5,5; 6,68 and 6,38 million USD respectively. 


\section{Conclusions}

The developed methodology and the software package provide:

- the selection of the optimal structure of the existing or advanced tug assistance of ports according to the types of tugs and their bollard pull, taking into account the individual characteristics of the port waters, the climate, the number of berths and the established regime of navigation;

- the determination of economic results of the secure service of ships, in the complex of the existing and expanded berths of the port with the existing or set structure of the tug fleet;

- the solution of the major problems of harbor tugs designing, in particular - the development of a number of types and sizes of tugs, depending on the required bollard pull.

Another application of the methodology and the software package is possible. In particular they can be used to solve the following problems:

- the operational solutions to all current tasks of escorting and mooring / unmooring of ships in the modern port using powerful tugs;

- development of the reform of "Mandatory requirements of the port to the number and power of tugs serving ships entering the port";

- preparation and correcting of the relevant chapters of "Norms of technological designing of seaports of Ukraine".

\section{ACKNOWLEDGMENTS}

The authors would like to acknowledge the Ksenija Tsytsiura in translating the Ukraine language materials.

\section{REFERENCES}

[1] “GD 31.31.37-78. Norms of Technological Designing of Seaports”, Fundamentals. Moscow, Minmorflot USSR Publ, 1978. (in Russian)

[2] “GD 31.3.05-97. Norms of Technological Designing of Seaports”, Moscow, Ministerstvo transporta Rossiyskoy Federatsii Publ, 1998. (in Russian)

[3] HENSEN, H.: "Tug Use in Port. A Practical Guide", Second edition. Port Rotterdam, Nautical Institute Publ., 2003.

[4] “Towage Guidelines Issue - The Bristol Port Company”, 2012.

[5] THORESEN, C.A.: "Port Designers' Handbook", 3rd Edition, ICE Publishing, London, 2014.

[6] YERMOLAEV, G.G.: "Handbook of the Sea Captain”, Moscow, Kniga po Trebovaniyu Publ, 2013. (in Russian)

[7] GÓRSKI, Z., GIERNALCZYK, M.: "Method for Determination of Energy Demand for Main Propulsion and Onboard Electric Power for Modern Harbour Tug Boats by Means of Statistics", Journal of KONES, Vol. 19, No. 1, p.147-154, 2012.

[8] BOGDANOV, B.V., SLUTSKII, A.V., SMAKOV, M.G., BASHLVEB, K.A., SORKIN, D.KH.: "Towing Vessels, Design and Construction", Sudostroyine, Leningrad, 1974 (in Russian).

[9] RADISIC, Z.: "Principal Types and Characteristics of Harbour Tugs", Promet- Traffic- Traffico, Vol. 15, No. 6, p. 381-386, 2003.

[10] ARTYSZUK, J.: "Types and Power of Harbour Tugs - the Latest Trends", Prace Naukowe Politechniki Warszawskiej. Transport, 2013.

[11] HESS S., HESS M., TOMAS V.: “A Way of Modeling the Port Operations”, Pomorstvo, Vol.23, No.1, p.137-154, 2009. 
[12] BUI, V. P., KAWAI, H., KIM, Y. B. AND LEE, K. S.: “A Ship Berthing System Design with Four Tugboats", Journal of Mechanical Science and Technology, 2011, 25(5). http://dx.doi.org/10.1007/s12206-011-0215-4.

[13] BRANDNER, P.A.: "Hydrodynamic Aspects of Shiphandling Tugs", 11th Australasian Fluid Mechanics Conference. University of Tasmania, Hobart, Australia, 14-26 December, 1992.

[14] ALYAVDINA, T.F.: "Development of Procedures for the Selection of Optimal Types and Number of Tugs for the Port", Cand. Diss. Leningrad, USSR, 1986. (in Russian)

[15] AGERSCHOU, H., DAND, I., ERNST, T.: "Planning and Designing of Ports and Marine Terminals", 2nd edition. London, Thomas Telford., 2004.

[16] GAYTHWAITE, J.W.: "Design of Marine Facilities for the Berthing, Mooring, and Repair of Ships", Reston, ASCE Press, 2004.

[17] YASUHIRO, A., HIRONAO, T.: "Ship Dimensions of Design Ship under Given Confidence Limits", Technical Note of the Port and Harbour Research Institute, No. 0911, 1998.

[18] HIRONAO, T., AYAKO, G., MOTOHISA, A.: "Study on Standards for Main Dimensions of the Design Ship", Technical Note of National Institute for Land and Infrastructure Management, No. 309, June, 2006.

[19] GNEDENKO, B.V., KOVALENKO, I.N.: "Introduction to Queuing Theory”, Moscow, Izdatelstvo LKI, 2007. (in Russian)

[20] SAATY, T.L.: "Elements of Queuing Theory with Applications", McGraw-Hill, New York, 1961.

[21] STEWART, W.J.: "Probability, Markov Chains, Queues, and Simulation: The Mathematical Basis of Performance Modeling", Princeton University Press, 2009.

[22] LAW, A.M.: "Simulation Modeling and Analysis": 5th edition, New York, McGraw-Hill Publ, 2015.

[23] CHAN, V.: “Theory and Applications of Monte Carlo Simulations", InTech, 2013, 2013.

[24] SOVETOV, B.YA., YAKOVLEV, S.A.: "Simulation of Systems”, Moscow, Vysshaya shkola Publ, 2009. (in Russian)

[25] RUTKOVSKAYA, D., PILINSKIY, M., RYTKOVSKIY, L.: "Neural Networks, Genetic Algorithms and Fuzzy Systems”, Moscow, Goryachaya liniya - Telekom Publ, 2006. (in Russian)

[26] SIVANANDAM, S.N., DEEPA, S.N.: "Introduction to Genetic Algorithms", New York, Springer Publ., 2007.

Submitted: $\quad 09.09 .2015$

Accepted: $\quad 23.03 .2016$.
Oleksandr V. Bondarenko, abondarenko70@mail.ru Valery O. Nekrasov

Oleksii P. Yastreba

Admiral Makarov National University of Shipbuilding,

Institute of Naval Architecture,

9, Geroev Stalingrada Av., 54025 Mykolaiv Ukraine 